\title{
The aetiology of experimental fibrosing alveobronchiolitis induced in rats by paprika dust
}

\author{
Erzsébet Tátrai, Gy Ungváry
}

\begin{abstract}
The effect of a single intratracheal dose of respirable paprika (Hungarian) dust, paprika dust extract, and cellulose dust on the lungs of rats was examined sequentially one and three months after a treatment. Treatment with respirable paprika and cellulose dusts resulted in alveobronchiolitis at the end of the first month and fibrotic changes at the end of the third month. As the extract of paprika dust caused no histopathological alterations, it is assumed that the high cellulose content of paprika was responsible for the histological reactions.
\end{abstract}

Epidemiological data indicate that some food and food additives can cause irritative symptoms in conjuctival and mucous membranes, or hypersensitive respiratory symptoms. ${ }^{1-4}$ The paprika splitter's lung described in Hungary ${ }^{2}$ proved to be pulmonary mycosis caused by Mucor stolonifer. ${ }^{5}$ Therefore its aetiology differs basically from the previously mentioned diseases, where the exact aetiology is unknown.

We have found that paprika dust free of fungi can also induce alveobronchiolitis with moderate fibrotic character. ${ }^{6}$ To clarify the aetiology we compared the effects of paprika dust extracts with the effects of paprika and cellulose dust. Cellulose is reported to be the largest component of paprika dust.

Materials and methods

Male CFY rats (Hungarian SD, LATI-Gödöllö, $250-280 \mathrm{~g}$ body weight at the outset of each experiment (five rats per group), were used. Test materials were commercial paprika dust (Szegedi Édes Nemes, MSZ 11851, particle size $<5 \mu \mathrm{m}$ ), extracts of paprika dust, and cellulose dust. The dusts were suspended in physiological saline containing $40000 \mathrm{IU}$ crystalline penicillin per $\mathrm{ml}$. One $\mathrm{ml}$ suspension contained $15 \mathrm{mg}$ of dust and one $\mathrm{ml}$ of paprika dust extract was made from $15 \mathrm{mg}$ paprika dust. The control solution was physiological saline.

National Institute of Occupational Health, Budapest, Hungary

E Tátrai, G Ungváry
Animals were treated intratracheally under superficial ether anaesthesia. The animals were killed by cutting the abdominal aorta during superficial ether narcosis at the end of the first and third months after treatment. The lungs, and cervical and hilar lymph nodes were removed.

\section{CONTROL GROUP}

Control animals received $1 \mathrm{ml}$ of physiological saline containing $40000 \mathrm{IU}$ crystalline penicillin.

\section{EXPERIMENT 1: RESPIRABLE PAPRIKA DUST}

Paprika dust was separated on a set of sieves (DIN 4188) with a 0.063 closing unit. This fraction was vapourised in a polyethylene "tent" by a ventilator and the suction engine of the hood. Dust that accumulated inside the "tent" was collected in the fine filter of a 2 SPG 210 stationary dust sampler, without the use of solvents, and was suspended in physiological saline containing penicillin. Each animal received $1 \mathrm{ml}$ of suspension as a single dose.

\section{EXPERIMENT 2: EXTRACT OF PAPRIKA DUST}

The paprika dust was sequentially extracted with dichloromethane and methanol with a Soxhlet extractor. Each extraction was run for six hours. Extracts were pooled and solvents removed under reduced pressure with a rotary flash evaporator and finally a nitrogen stream. Residues were suspended in physiological saline containing penicillin. Each animal received $1 \mathrm{ml}$ of suspended extract as a single dose.

EXPERIMENT 3: RESPIRABLE CELLULOSE DUST

Cellulose dust (Cellulosepulver MN 300 for thin layer chromatography, Macherey Nagel 5160 Düren, Germany) was suspended in physiological saline containing penicillin. Each animal received $1 \mathrm{ml}$ of suspended cellulose dust as a single dose.

\section{HISTOPATHOLOGICAL EXAMINATIONS}

Lungs, and hilar and cervical lymph nodes were fixed in $10 \%$ neutral buffered formalin and embedded in paraffin. Sections were stained with haematoxylin and eosin ( $\mathrm{H}$ and $\mathrm{E})$ and submitted to an aldehyde bisulphite-toluidine blue (ABT) reaction, ${ }^{7}$ periodic acid-Schiff (PAS) staining, and Gömöri's silver impregnation. 


\section{Results}

The lungs and lymph nodes of control animals showed no histopathological alterations one and three months after treatment.

\section{EXPERIMENT 1: RESPIRABLE PAPRIKA DUST}

Peribronchial and intra-alveolar changes were seen in all rats one month after treatment. There were foci containing lymphocytes, plasma cells, macrophages, and few fibroblasts. In the cytoplasm of macrophages some phagocytosed, irregularly shaped foreign bodies were seen (fig 1a); these were PAS positive and greenish birefringent with the ABT reaction between crossed polars. Mature sinus histocytosis occurred in hilar and cervical lymph nodes. Three months after treatment the interstitium of the lungs was thickened in the vicinity of the developed foci. In intrabronchiolar and intraalveolar foci foreign body type giant cells could be seen (fig 1b); phagocytosed foreign bodies were found in the cytoplasm that were

Figure 1a Rat lung $\times 300$. Single intratracheal administration of respirable paprika dust, 15 mg/animal (applies also to figures $1 b$ and $1 c$ ). One month after treatment; $H$ and $E$ staining. The alveoli are filled with granulation tissue consisting of lymphocytes, plasma cells, macrophages, and some fibroblasts. Foreign body fragments are present inside the macrophages $(\rightarrow)$.

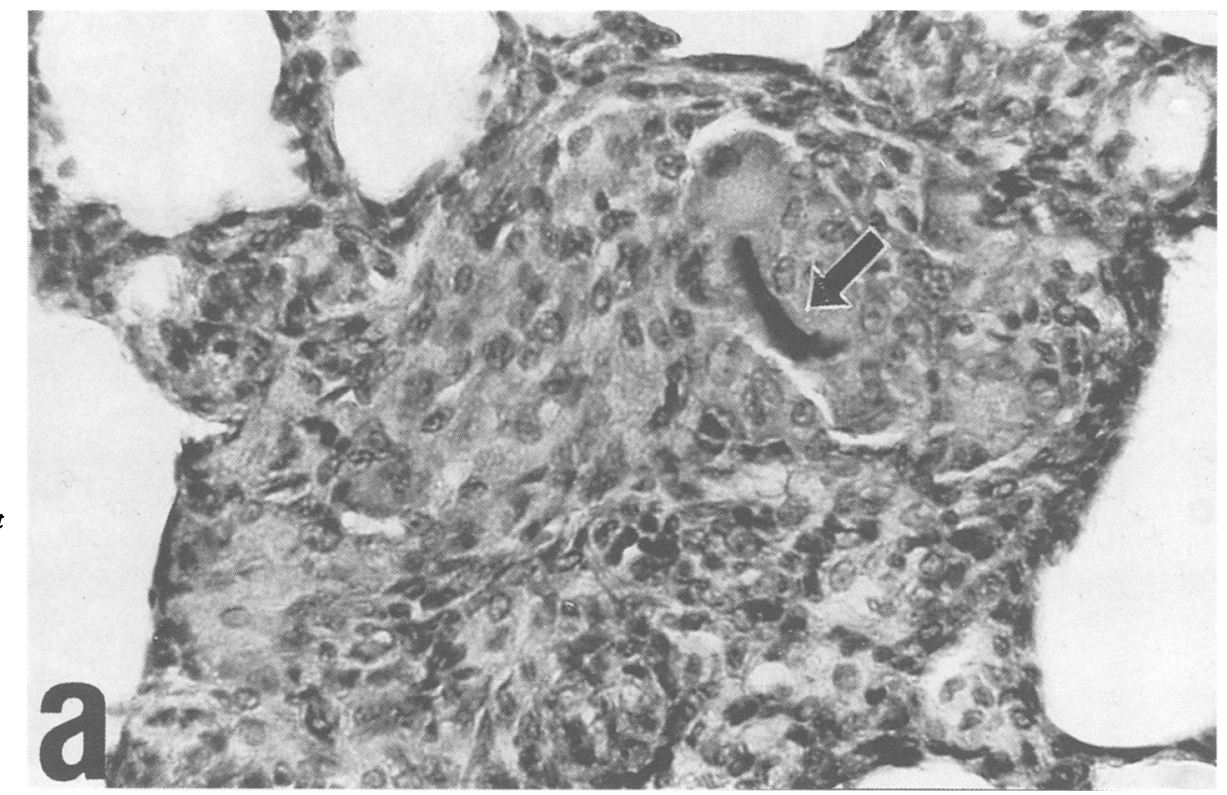

Figure $1 b$ Three months after treatment; $H$ and $E$ staining. Many multinucleated giant cells are present in the intra-alveolar granulation tissue with phagocytosed fragments in their cytoplasm.

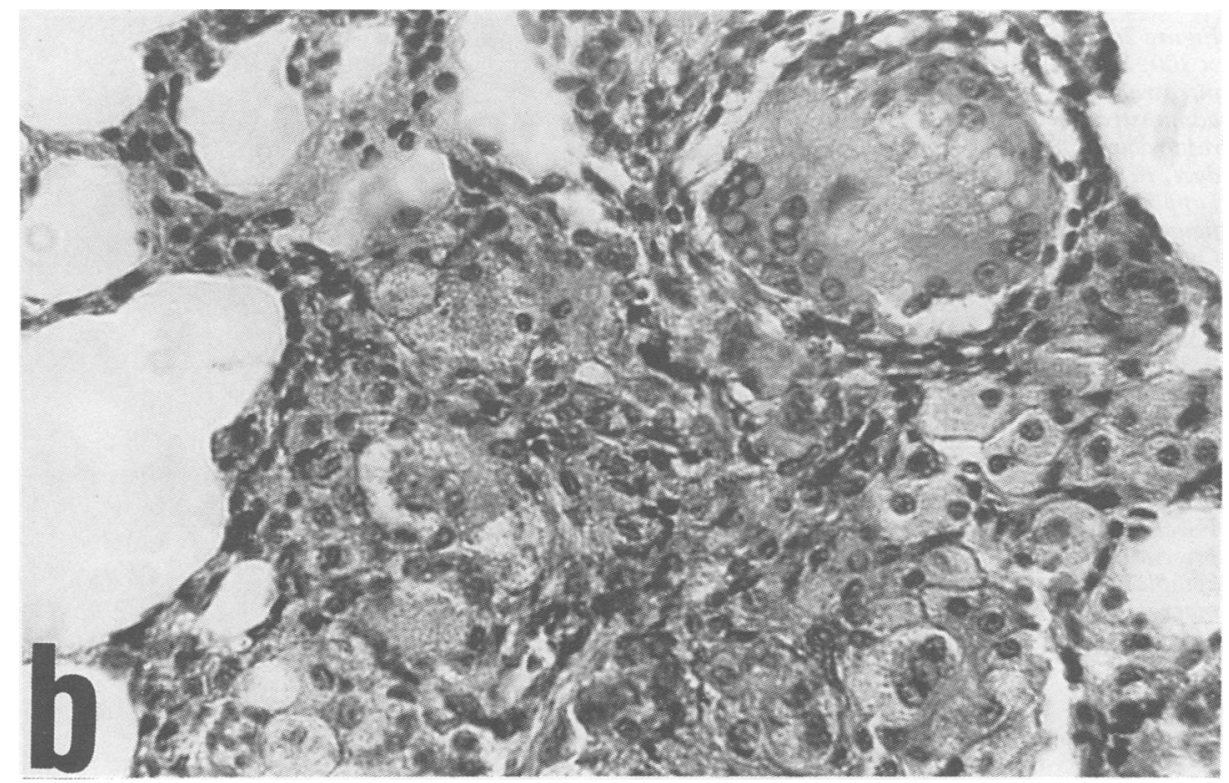


positively birefringent under polarised light. Some delicate argyrophilic fibres were detected inside the granulation tissue (fig 1c). The presence of mature sinus histiocytosis was seen in the lymph nodes.

\section{EXPERIMENT 2: PAPRIKA DUST EXTRACT}

At the end of the first and third months no pathological changes were found in the lungs and lymph nodes.
EXPERIMENT 3: RESPIRABLE CELLULOSE DUST

One month after treatment all animals had granulation tissue containing lymphocytes, plasm cells, and macrophages around the bronchi and inside the alveoli. Some irregularly shaped foreign bodies were seen inside the macrophages (fig 2a). These bodies were PAS positive and greenish birefringent with the ABI reaction between crossed polars. Three months after treatment several multinucleated foreign body
Figure 1c Three months after

treatment; Gömöri's silver impregnation.

The granulation contains a delicate, argyrophilic fibre network.

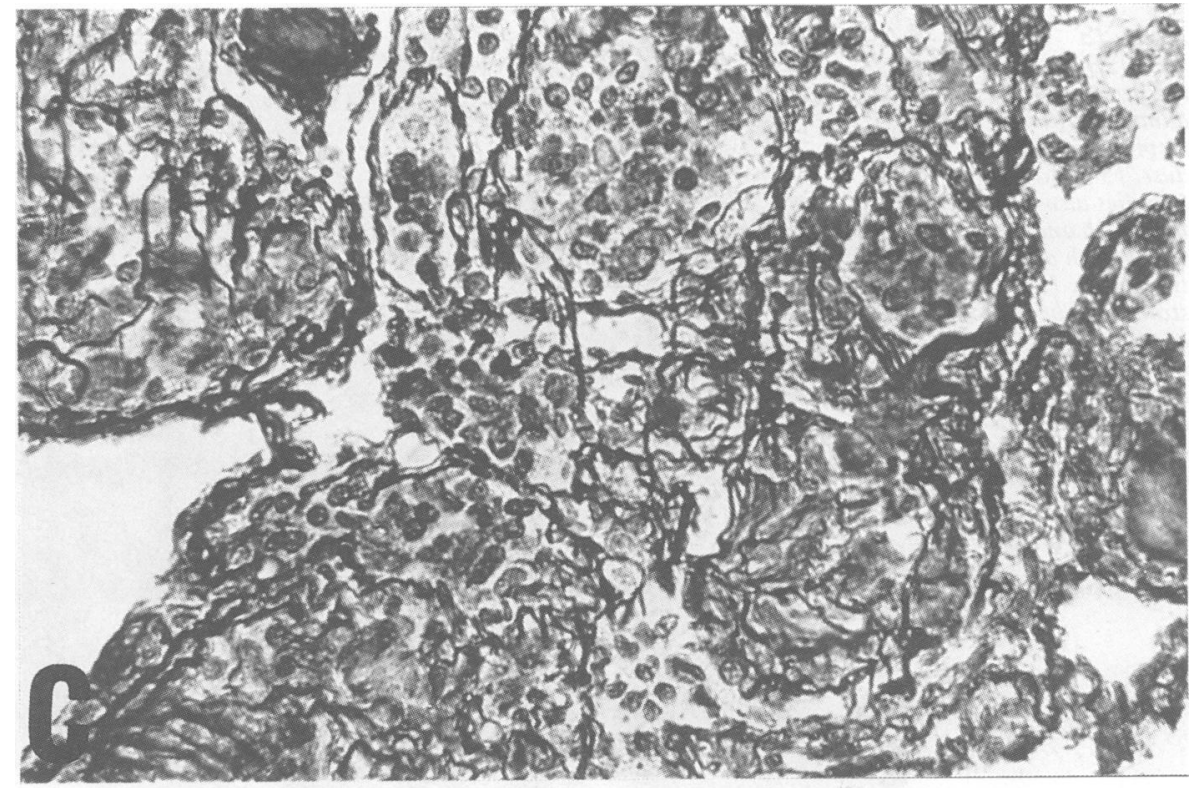

Figure 2a Rat lung $\times 300$. Single intratracheal administration of respirable cellulose dust, $15 \mathrm{mg} /$ animal (applies also to figures $2 b$ and $2 c$ ). One month after treatment, $H$ and $E$ staining. The alveoli contains

inflammatory granulation tissue consisting of lymphocytes, plasma cells, and macrophages. Foreign bodies are present in the cytoplasm of macrophages $(\rightarrow)$.

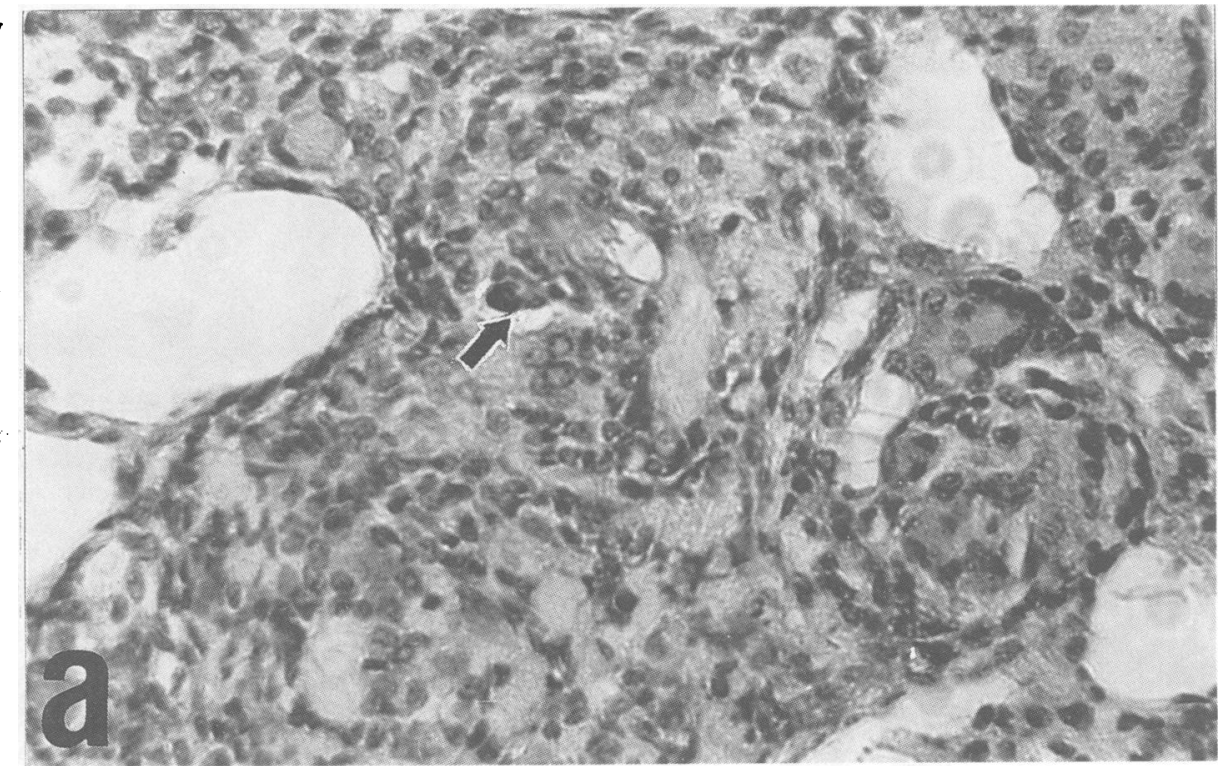


giant cells were seen in the granulation tissue filling the lumina of bronchioli and alveoli (fig 2b) with fragments showing positive birefringency in the cytoplasm. A delicate argyrophilic network was developed in the interstitium and the granulation tissue (fig 2c). Mature sinus histiocy tosis was found in the hilar and cervical lymph nodes.

\section{Discussion}

The aetiology and aetiopathogenesis of pulmonary histological reactions induced by plant dusts have not been clarified. ${ }^{8}$ In our earlier experiment with nonrespirable paprika dusts, ${ }^{6}$ we found that foreign bodies resembling the morphology of cellulose ${ }^{7}$ were present in developing fibrosing alveobronchiolitis. These findings have raised the possibility that the cellulose dust fraction as well as the high percentage $(20 \%)$ of cellulose in Hungarian paprika grists may have-at least to some extent - an aetiological role in the development of granulation. The effect of
Figure $2 b$ Three months after

treatment; $H$ and $E$ staining. The intraalveolar granulation tissue contains many foreign body type giant cells.

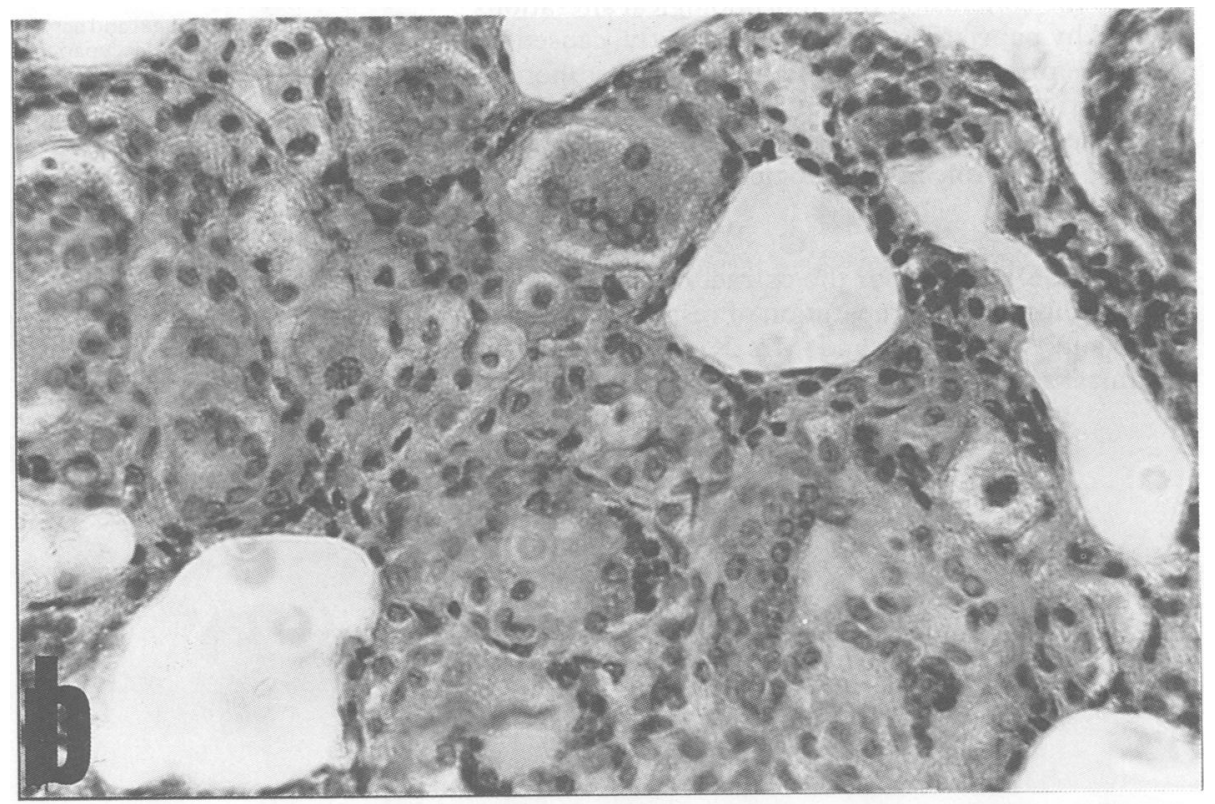

Figure 2c Three months after treatment; Gömöri's silver impregnation. Some argyrophilic fibres are present in the granulation tissue.

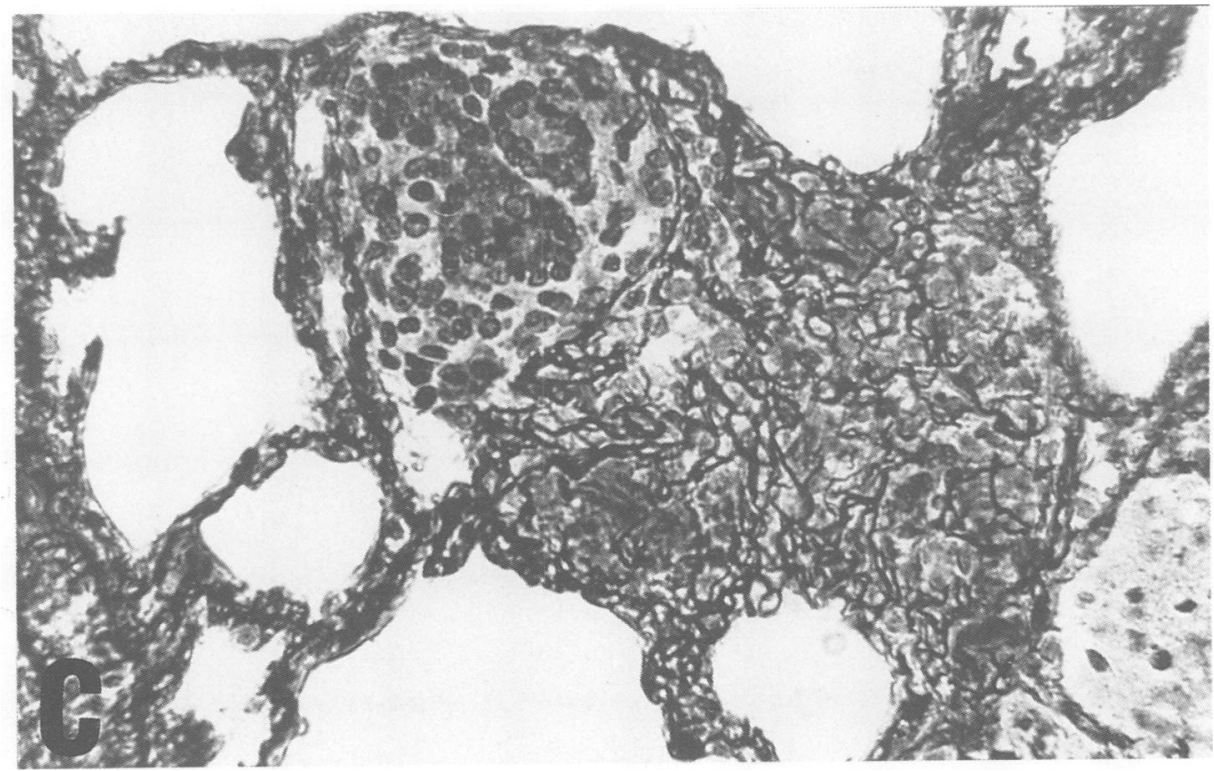


cellulose dust on human tissues has not been determined so far.

After intratracheal treatment with respirable paprika or cellulose dusts, identical histological changes developed after one and three monthsnamely, chronic inflammatory foreign body granulation with intrabronchiolar and intra-alveolar appearance, which showed mild and moderate fibrosing character. Despite its high concentration of biologically active materials, ${ }^{9}$ the extract of paprika dust resulted in no histological changes. The findings lead to the conclusion that morphological alterations caused by paprika dust are, at least partly, caused by cellulose present in grists and a constant component of plant cell walls. It may be assumed that the cellulose content of other plant dusts may also have an aetiological role in pathological changes caused by such dusts.

We thank Dr Török for the extract of paprika dust, Mrs Mohos for the preparation of respirable paprika dust, and Mrs Király and Mrs Krausz for skillful technical assistance.
Requests for reprints to: Erzsébet Tátrai, $\mathrm{MD}, \mathrm{PhD}$, National Institute of Occupational Health, Budapest, H-1450 POB 22, Hungary.

1 Fink JN. Organic dust-induced hypersensitive pneumonitis. $J$ Occup Med 1973;15:245-7.

2 Uragoda CG. Symptoms among chilli grinders. $\mathrm{Br} J$ Ind Med 1967;24:162-5 (cites Hunter D. The diseases of occupations. London: English Universities Press, 1955).

3 Uragoda CG. Asthma and other symptoms in cinnamon workers. Br J Ind Med 1984;41:224-7.

4 Zuskin E, Kanceljak B, Skuris Z, et al. Immunological and respiratory findings in spice-factory workers. Environ Res 1988;47:95-108.

5 Lacey J, Crook B. Fungal and actynomycete spores as pollutants of the workplace and occupational allergens. Ann Occup Hyg 1988;32:515-33.

6 Tátrai E, Ungváry Gy. On the examination of the bronchopulmonary toxic effect of paprika dust in Wistar rats. Munkavédelem 1989:20-2. (In Hungarian.)

7 Romhányi Gy, Deák Gy, Fischer J. Aldehyde bisulfite-toluidine blue (ABT) staining as a topo-optical reaction for demonstration of linear order of vicinal $\mathrm{OH}$ groups in biological structures. Histochemistry 1975;43:333-48.

8 Parkes WR. Occupational lung disorders. 2nd ed. London: Butterworths, 1982:359-406.

9 Somos A. Paprika. Budapest: Akadémiai Kiadó, 1966:61. (In Hungarian.)

Accepted 4 November 1991 